\title{
Short-Term Host Selection Pressure Has Little Effect on the Evolution of a Monoclonal Population of Verticillium dahliae Race 1
}

\author{
Krishna D. Puri, Suraj Gurung, Dylan P. G. Short, Z. K. Atallah, German Sandoya, R. Michael Davis, Ryan J. Hayes, \\ and Krishna V. Subbarao ${ }^{\dagger}$
}

First, third, sixth, and eighth authors: Department of Plant Pathology, University of California, Davis; second author: Sakata Seed America, Salinas, CA; fourth author: Hartnell College, Salinas, CA 93905; fifth author: Department of Horticultural Science, Everglades Research and Education Center, University of Florida, Belle Glade; and seventh author: United States Department of Agriculture-Agricultural Research Service, Salinas, CA.

Accepted for publication 23 June 2017.

\begin{abstract}
Understanding pathogen evolution over time is vital for plant breeding and deployment of host resistance. In the context of a soilborne pathogen, the potential of host-directed evolution of a Verticillium dahliae race 1 isolate and genotypic variation of $V$. dahliae associated with two major hosts (lettuce and tomato) were determined. In total, 427 isolates were recovered over 6 years from a resistance screening nursery infested with a single $V$. dahliae race 1 isolate. In a separate study, an additional 206 isolates representing 163 and 43 isolates from commercial lettuce and tomato fields, respectively, were collected. Analyses of isolates recovered from the screening nursery over 6 years revealed no changes in the race

and mating type composition but did uncover seven simple sequence repeat (SSR) variant genotypes. No significant genotypic variation in V. dahliae was observed between or within fields of either lettuce or tomato but pathogen populations were significantly differentiated between these two hosts. Replicated virulence assays of variant SSR genotypes on lettuce differential cultivars suggested no significant difference in virulence from the wildtype race 1 isolate introduced into the field. This suggests that deployed race 1 host resistance will be robust against the widespread race 1 populations in lettuce-growing regions at least for 6 years unless novel pathogen genotypes or races are introduced into the system.
\end{abstract}

Deployment of major resistance $(R)$ genes in commercial cultivars and sustaining their efficacy over time under agricultural conditions is a significant challenge. Generally, plant disease resistance governed by a single major gene has a higher chance of being compromised than resistance controlled by multiple genes. The deployment of the $R$ gene in a host and its subsequent widespread use could select for pathogen populations that compromise deployed resistance (McDonald and Linde 2002). Plant pathogens with a higher mutation or substitution rate, a higher rate of migration or gene flow, larger effective population size, and mixed reproductive systems are predicted to have a relatively high evolutionary potential and, therefore, are able to overcome major $R$ genes more quickly than those with lower evolutionary potential (Gossmann et al. 2012; McDonald and Linde 2002). For example, the commercial wheat 'Gene', which contains the major $R$ gene Stb4 against Zymoseptoria tritici (Septoria tritici blotch), became highly susceptible within 5 years of its release (Cowger et al. 2000). Therefore, it is useful to understand how pathogen populations evolve, so as to predict the durability of $R$ genes over time.

Verticillium dahliae is a destructive soilborne pathogen that causes Verticillium wilt on many economically important crops, including artichoke, cotton, lettuce, pepper, strawberry, and tomato (Atallah et al. 2011; Pegg and Brady 2002; Subbarao et al. 1997). The fungus internally colonizes the vascular tissues while the host is still alive and, once the host reaches maturity, the fungus forms melanized resting structures called microsclerotia (Vallad and Subbarao 2008). Microsclerotia can remain viable in soil more than 20 years in the absence of susceptible plant tissue (Agrios 2005). In the absence of soil

†Corresponding author: K. V. Subbarao; E-mail: kvsubbarao@ucdavis.edu

K. D. Puri, S. Gurung, and D. P. G. Short contributed equally to this work. fumigants such as methyl bromide and chloropicrin, yield losses can reach up to $100 \%$ for lettuce crops (Subbarao et al. 1997). Regardless of the Verticillium wilt management technique employed, the inoculum can quickly rebound with repeated planting of the susceptible host (Chellemi et al. 2016; Short et al. 2015b). In addition, due to the harmful effects on the environment, some of the most widely used soil fumigants such as methyl bromide are no longer available for agricultural soil fumigation (Chellemi et al. 2016), although certain crops may seek critical use exemptions in the future. Thus, the deployment of effective host resistance will be the most practical and environmentally sustainable option for controlling Verticillium wilt in lettuce (Hayes et al. 2007; Sandoya et al. 2016).

Two pathogenic races (race 1 and 2) have been characterized for $V$. dahliae using differential lettuce and tomato cultivars (Schaible et al. 1951; Vallad et al. 2006). The Verticillium resistance 1 (Vrl) gene locus in 'La Brillante' lettuce (Hayes et al. 2011a; 2011c) confers resistance to $V$. dahliae isolates that secrete the effector Ave1 (de Jonge et al. 2012). In tomato, the Ve locus confers resistance to $V$. dahliae isolates that express the Avel virulence factor but there is an ongoing debate about which gene at this locus acts to activate defense responses (Castroverde et al. 2016). Plant resistance loci homologous to the Ve locus have ancient origins and have been characterized in several plants, including potato (Simko et al. 2004), cotton (Chen et al. 2016), and mint (Vining and Davis 2009).

$V$. dahliae race 1 resistance sources have been identified in several lettuce germplasm accessions and are being incorporated into commercial cultivars (Hayes et al. 2007). Only partial resistance has been identified in some plant introductions against race 2 (Hayes et al. 2011b; Sandoya et al. 2016). Race 2 isolates from tomato have been further split into two races (race 2 and 3 ) in Japan (Usami et al. 2016), though the existence of race 3 in other host systems is unknown at this time.

In the Salinas valley of California, an important lettuce-growing region, $V$. dahliae race 1 is more prevalent and widespread than race 2 (Gurung et al. 2014). Thus, the deployment of lettuce cultivars with 
$V r l$ will be useful for Verticillium wilt management in lettuce. It has been estimated that monogenic resistance might collapse in as little as 4 to 5 years in the presence of pathogens with high evolutionary potential, especially pathogens that undergo sexual recombination (McDonald and Linde 2002). Field-based studies to determine the effect of $R$-gene-selective pressure on genotypic diversification in asexually reproducing fungal species, including $V$. dahliae, are infrequent in the literature. There is evidence that the evolution of race 2 through loss of Ave1 has occurred multiple times in a multitude of $V$. dahliae lineages (de Jonge et al. 2013) but estimating the evolutionary potential of individual $V$. dahliae genotypes over time has not been attempted, and no information is available on the impact of host $R$-gene-selective pressure on the evolution of $V$. dahliae races. In theory, host selection pressure can select for mutations in fungal avirulence genes, leading to loss of host resistance (Leach et al. 2001). Resistant host genotypes could eventually select for mutants lacking the avirulence gene, though the time frame in which this would happen in lettuce is unclear.

V. dahliae is known for its broad host range, and isolates from various hosts are consistently cross-pathogenic when tested experimentally (Bhat and Subbarao 1999; Iglesias-Garcia et al. 2013; Sandoya et al. 2016). Some cause more damage in some hosts than in others (Bhat and Subbarao 1999; Douhan and Johnson 2001; Koike et al. 1994; Subbarao et al. 1995) and, usually, isolates are most virulent on the host from which they were originally isolated. For this reason, isolates are described as host-adapted rather than hostspecific, which may reflect differences in pathogenicity and virulencerelated genes (Cirulli et al. 2010). It has been posited that host jumps have led to severe disease outbreaks in some crops (Koike et al. 1994; Qin et al. 2006). The results of a large-scale survey of the diversity of $V$. dahliae from different hosts revealed a limited number of surprisingly common genotypes found on a range of crops and across a wide geographic sampling, whereas other $V$. dahliae genotypes appeared to have much stronger associations with certain hosts (Short et al. 2015a). Whether or not the exclusive association of $V$. dahliae with a specific crop is a reflection of host adaptation or simply a consequence of sampling evolutionarily and geographically divergent populations remains unclear. Thus, understanding the diversity and population structure of $V$. dahliae associated with economically important crops and their possible cross-movement is crucial for long-term Verticillium wilt management. It is important to understand the dynamics of a single V. dahliae genotype over time and the dynamics of natural populations within and between commercial fields.

In this study, we evaluated genotypic changes in a monoclonal pathogen population over time after introduction into a nursery planted with repeated lettuce genotypes of varying levels of disease resistance. The objectives of this study were to (i) understand whether host- $R$-gene-directed pathogen evolution is a possibility in $V$. dahliae; (ii) explore whether mutation or loss of the avirulence gene Avel can be detected over the course of a multiyear study; and (iii) determine the level of genotypic variation within and between populations of $V$. dahliae in lettuce and tomato fields within California.

\section{MATERIALS AND METHODS}

Disease nursery establishment. A $V$. dahliae race 1 disease nursery ( 45 by $40 \mathrm{~m}^{2}$ ) was established in a research field at the United States Department of Agriculture (USDA) Research Station, Salinas, CA. The nursery had no previous history of $V$. dahliae infestation and was fumigated with a mixture of methyl bromide $(67 \%)$ and chloropicrin $(33 \%)$ at $361 \mathrm{~kg} / \mathrm{ha}$ in 2009 . Postfumigation soil assays revealed no Verticillium spp. (data not shown). Precautions were exercised throughout the study to restrict the inadvertent movement of soil and infested plant material into and out of the nursery. Practices followed throughout the study included cleaning of farm equipment, wearing boot covers, autoclaving used boot covers, and so on. The uniformity of inoculum distribution in the disease nursery soil was established by transplanting $V$. dahliae race-1-inoculated susceptible 'Salinas' lettuce. Briefly, the disease nursery was transplanted with approximately 10,000 seedlings of lettuce cultivar Salinas that were prepared and inoculated with $V$. dahliae race 1 isolate Ls16 in a greenhouse. Isolate Ls16 was collected from a commercial lettuce field at Watsonville, CA in 1996, and has been sequenced, well characterized, and is now broadly used in lettuce breeding programs to screen germplasm for race 1 resistance (Hayes et al. 2007, 2011a,c). Prior to transplanting, seedlings were grown in 128-well plug trays in the greenhouse at 22 to $26^{\circ} \mathrm{C}$ with a $16-\mathrm{h}$ photoperiod and inoculated three times at weekly intervals with $3 \mathrm{ml}$ of a spore suspension of $1 \times 10^{7}$ conidia/ml beginning at 2 weeks after seedling emergence. Seedlings were further maintained in the greenhouse for an additional 2 weeks after the last inoculation, acclimatized outside the greenhouse for 10 days, then transplanted in the disease nursery. Inoculated transplants were grown in two rows per 1-m-wide bed, which is standard for lettuce production in coastal California. Plant spacing was approximately $28 \mathrm{~cm}$ between rows and $28 \mathrm{~cm}$ between plants within a row. Plants were grown until maturity and incorporated entirely into the soil by disking and redistributing the soil. The process was repeated in the spring and fall seasons of 2009 and 2010. From 2010 to 2015 , the nursery has been in use for screening lettuce germplasm and breeding lines, with soil inoculum density maintained at a high level (>100 microsclerotia $\mathrm{g}^{-1}$ of soil) through inoculum augmented by susceptible lines. Experimental lettuce material in these experiments consisted of early and intermediate generation families and inbred lines derived from crosses to incorporate race 1 resistance from La Brillante (race 1 resistant, $V r l$ ) and other cultivars, including iceberg, romaine, and leaf-type lettuce. This represented approximately $45 \%$ of the test plot area. Another $5 \%$ of the test plot area was occupied by plant introductions that were selected for partial resistance to race 2 isolates in a greenhouse experiment and were being evaluated for resistance to race 1 in a field experiment. The remaining plots were occupied by susceptible germplasm. At the end of each growing season, plants were incorporated into the soil by disking, and the subsequent lettuce lines were planted in different positions in the nursery, following a randomization procedure.

Isolate collections from the disease nursery. Each spring and fall, varying numbers of $F_{1}$ and $F_{2}$ families from crosses between La Brillante $(V r l)$ and crisphead lettuce cultivars or the recombinant inbred line populations derived from Salinas $(v r l)$ and La Brillante $(V r l)$ were evaluated in the disease nursery for resistance to Verticillium wilt. After disease evaluations, roots from arbitrarily selected diseased plants were collected in spring 2010, 2011, 2012, 2013, 2014, 2015, and fall 2013 (a total of seven “populations"). Each year, approximately 100 to 120 symptomatic root samples representing the entire disease nursery were collected and processed for $V$. dahliae isolation. The roots were transported to the laboratory, washed thoroughly to remove any soil, and surface disinfested with $0.5 \%$ sodium hypochlorite for 3 to $5 \mathrm{~min}$, followed by a 2- to 3-min rinse with sterilized distilled water. Roots were dried in a laminar flow hood, sliced into approximately 1-mm cross-sections, and plated on the semiselective NP-10 medium (Kabir et al. 2004) enriched with two antibiotics (streptomycin sulfate and chlortetracycline $\mathrm{HCl}$ at 100 $\mathrm{ppm}$ each). Plates were incubated at room temperature $\left(23 \pm 2^{\circ} \mathrm{C}\right)$ until microsclerotia were observed around plated tissue. A small section of the agar with mycelium and visible microsclerotia was transferred to potato dextrose agar (PDA) plates and incubated for an additional week. Conidia were then streaked onto a new PDA plate and a single conidial colony was further transferred onto a new plate. Cultures were then prepared for long-term storage in $25 \%$ glycerol or for DNA extraction.

DNA extraction and polymerase chain reaction. Two 3-mmdiameter $V$. dahliae plugs from an actively growing fungal colony on PDA were transferred to $50 \mathrm{ml}$ of potato dextrose broth and grown for 7 to 10 days on laboratory benches at room temperature $(23 \pm$ $2{ }^{\circ} \mathrm{C}$ ). Mycelium was harvested, washed, and lyophilized for $24 \mathrm{~h}$. The genomic DNA was extracted from lyophilized tissue using a FastDNA Kit (MP Biomedical, Santa Ana, CA) following the manufacturer's instructions, quantified using a NanoDrop 1000 
spectrophotometer (Thermo Fisher Scientific, Wilmington, DE), and diluted to $25 \mathrm{ng} / \mu \mathrm{l}$ for downstream applications.

Verticillium spp., mating type, and race designations. Verticillium isolates were characterized using primers specific for species, race, and mating type. Briefly, isolates were first tested using V. dahliae, V. isaacii, V. klebahnii, and V. tricorpus multiplex polymerase chain reaction (PCR) primers (Df/Dr, If/IKr, Kf/IKr, and $\mathrm{Tf} / \mathrm{AaTr}$, respectively), as previously described (Inderbitzin et al. 2013). The multiplex produces amplicons of 490, 195, 230, and $415 \mathrm{bp}$, respectively. The mating type multiplex PCR was used to amplify the MAT1-1-1 and MAT1-2-1 idiomorphs of $V$. dahliae using primers Alf3/MAT11r for MAT1-1-1, and HMG21f/MAT21r for MAT1-2-1, as previously described (Inderbitzin et al. 2011), which amplified 600- and 300-bp fragments from MAT1-1-1 and MAT1-2-1, respectively. The race affiliation of $V$. dahliae isolates was determined separately by using race 1 - and race 2 -specific primers following PCR conditions described by Gurung et al. (2014). The Avel effector gene-specific primers (VDAve1F and VDAve1R) were used to determine $V$. dahliae race 1 isolates (de Jonge et al. 2012) while primers designed to amplify a 256-bp exonic region of the VDAG_05863.1 putatively conserved in race 2 from V. dahliae Ls17 were used to designate race 2 (Short et al. 2014b).

All PCR were performed in a 25- $\mu$ l volume containing $12.5 \mu \mathrm{l}$ of $2 \times$ GoTaq Green Master Mix (Promega Corp., Madison, WI), $2 \mu \mathrm{l}$ of genomic DNA $(25 \mathrm{ng} / \mu \mathrm{l}), 1 \mu \mathrm{l}(10 \mu \mathrm{M})$ of each primer, and $8.5 \mu \mathrm{l}$ of nuclease-free water (Promega Corp.). PCR were run in a ProFlex 2-by-96-well PCR system (Thermo Fisher Scientific Inc.). The amplicons were visualized in $1.25 \%$ (wt/vol) agarose gels prestained with $0.03 \%$ 1000x GelRed (Biotium, Inc., Fremont, CA) and run for $50 \mathrm{~min}$ at $95 \mathrm{~V}$ in $0.5 \%$ Tris-borate-EDTA buffer. An ultraviolet transilluminator (UVP, LLC, Upland, CA) was used for PCR product visualizations referenced to a 100-bp DNA ladder (Invitrogen Life Technologies, Carlsbad, CA).

Microsatellite genotyping. Thirteen simple sequence repeat (SSR) loci designed from the genome of $V$. dahliae isolate Ls17 located on five chromosomes (Ch)_VD8, VD9, VD10, VD11, and VD12 (Ch 1); VD1, VD2, VD3, and VD97 (Ch 2); VD27 (Ch 3); VD92 (Ch 6); and VD69 and VD73 (Ch 8) — were used in this study (Almany et al. 2009). The forward primer of each primer sequence was labeled with either 6-FAM, VIC, NED, or PET fluorescence dye at the 5' ends. PCR were prepared in $20-\mu l$ total volumes containing $10 \mu \mathrm{l}$ of $2 \times$ GoTaq Colorless Master Mix (Promega Corp.), $1 \mu \mathrm{l}$ of $5 \mu \mathrm{M}$ each reverse and forward primer, $2 \mu \mathrm{l}$ of genomic DNA at $25 \mathrm{ng} / \mu \mathrm{l}$, and $6 \mu \mathrm{l}$ of nuclease-free water (Promega Corp.). The PCR thermal profiles consisted of $5 \mathrm{~min}$ of initial denaturation at $94^{\circ} \mathrm{C}$; followed by 35 cycles of $30 \mathrm{~s}$ at $95^{\circ} \mathrm{C}, 20 \mathrm{~s}$ at $55^{\circ} \mathrm{C}$, and $30 \mathrm{~s}$ at $72^{\circ} \mathrm{C}$; with a 10 -min final extension at $72^{\circ} \mathrm{C}$. Agarose gel-confirmed amplicons were poolplexed by adding $7 \mu \mathrm{l}$ of each of the four labeled PCR products into a 96-well PCR plate and sent for fragment analysis to the DNA Sequencing Facility, University of California, Davis. The sequencing facility used $1 \mu \mathrm{l}$ of pooled multiplex mixture combined with Hi-Di formamide and $0.3 \mu \mathrm{l}$ of LIZ-500 size standard and loaded into an ABI 3100 capillary electrophoresis genetic analyzer (Applied Biosystems, Carlsbad, CA) system for fragment separation. The $V$. dahliae race 2 isolate $\mathrm{Ls} 17$ was used as a reference isolate for each primer set. Isolates identified as variants of a particular SSR locus were confirmed using DNA sequencing.

Greenhouse experiments. To test the possibility that SSR mutants had functional changes to Avrl that was undetectable with PCR, the race of mutant genotypes was confirmed phenotypically by pathogenicity tests using the lettuce differential cultivars La Brillante $(V r l)$ and Salinas $(v r l)$ in the greenhouse. Further, representative mutant isolates were tested on susceptible 'Long Purple' eggplant and compared with the wild-type Ls16 isolate. The assay was performed in styrofoam cups $(350 \mathrm{ml})$ filled with a sterilized sandpotting soil mix (2:1, vol/vol; SunGro, Watsonville, CA) arranged in a randomized complete block design with three blocks and three plants per block. Seeds were sown in 128-square-deep cell plug trays
(McConkey Company, Garden Grove, CA) filled with Sunshine Mix Number 4 (SunGro Horticulture, Agawam, MA). Two-weekold seedlings were inoculated by drenching each tray cell with $3 \mathrm{ml}$ of conidial suspension $\left(1 \times 10^{7} / \mathrm{ml}\right)$. Seedlings were transplanted into the sand-potting soil mix and inoculated weekly for an additional 2 weeks. The standard V. dahliae race 1 isolate Ls 16 and waterinoculated plants were used as controls. Disease severity was assessed at 10 weeks after the final inoculation using a standard subjective ordinal rating scale (0 to 5 ) based on root discoloration and foliar symptoms, as described by Hayes et al. (2011c).

Isolate collection from lettuce and tomato fields. In a separate study, three commercial lettuce fields and one commercial tomato field, all with a history of Verticillium wilt, were sampled. Lettuce roots were collected in 2009 and 2010 from diseased fields in Monterey County, CA while tomato roots were collected in 2012 from a field in Yolo County, CA (Fig. 1). A systematic hierarchical sampling method was adopted in all years using three $25-$ by $-25-\mathrm{m}^{2}$ grids approximately $75 \mathrm{~m}$ apart in each field. Within a grid, an infected plant was uprooted from every 5 to $10 \mathrm{~m}$ and returned to the laboratory for fungus isolation. An additional plant next to the infected plant in the same bed and two infected plants from adjoining beds were also collected. The sample processing, single spore isolation, DNA extraction, PCR for species composition, race structure, mating type, and SSR genotyping were done as described above.

Population genetic analysis. Alleles generated from 13 SSR loci were assigned based on the PCR size amplicons using GeneMarker v2.6.4 (SoftGenetics, Oakland, CA). Isolates having identical multilocus genotypes (MLG) and mating type were considered clones (asexual progeny). Data sets were clone corrected at either the grid or field level for genetic analysis unless otherwise stated. For the hierarchical field study, isolates were organized into "grids" within "fields". Three lettuce fields (Cooper1, Cooper2, and Harkins) had three grids each, totaling nine grid populations in lettuce: Copper1-Grid1 (C1G1), Cooper1-Grid2 (C1G2), Cooper1-Grid3 (C1G3), Cooper2-Grid1(C2G1), Cooper2-Grid2 (C2G2), Cooper2Grid3 (C2G3), Harkins-Grid1(HG1), Harkins-Grid2 (HG2), and Harkins-Grid3 (HG3). One tomato field was also divided into three grids: Yolo-Grid1 (YG1), Yolo-Grid2 (YG2), and Yolo-Grid3 (YG3). The genotypic variability associated with lettuce and tomato was analyzed using combined data from the three lettuce fields. In addition, the isolates from the race 1 disease nursery were grouped into seven separate populations based on year and season of collection: 2010, 2011, 2012, 2013 fall, 2013 spring, 2014, and 2015, respectively.

Genetic distance $(D)$, Nei's unbiased gene diversity $(H)$ (Nei 1973), and gene flow ( $\mathrm{Nm}$ ) (McDermott and McDonald 1993) between populations were analyzed using POPGENE v1.32 (Yeh et al. 1997). MLG and genotype diversity analyses were performed using an R package for population genetics analysis (Poppr) (Kamvar et al. 2014). The standardized index of linkage disequilibrium ( $r$ BarD) was calculated to test the nonrandom association of alleles at different gene loci using Poppr (Kamvar et al. 2014). Analysis of molecular variance (AMOVA), gene flow $(\mathrm{Nm})$, and pairwise population differentiation between populations (PhiPT), fields (PhiPR), and grids $(P h i R T)$ in lettuce or between two hosts were estimated using GenAlEx 6.5 (Peakall and Smouse 2012). The proportion of fungal isolates originating from asexual reproduction (clonal fraction) was calculated by $1-[$ (number of unique genotypes)/(total number of isolates sampled)]. A principal component analysis (PCA) of lettuce and tomato genotypes was performed on a similarity matrix using DECENTER and EIGEN functions in NTSYSpc (version 2.1, 2000, Applied Biostatistics Inc., Port Jefferson, NY).

\section{RESULTS}

Verticillium spp., mating type, and race identification. Disease nursery. In total, 427 isolates $(63,33,37,96,73,31$, and 94 from 2010, 2011, 2012, 2013 spring, 2013 fall, 2014, and 2015, respectively) were recovered from lettuce roots from the disease 
nursery. Verticillium spp.-specific PCR identified only $V$. dahliae from recovered isolates. Further, DNA from all isolates amplified with effector Ave1-specific primers, confirming that they were race 1 similar to the original genotype introduced into the field, and had only the MAT1-2-1-specific amplicon.

Field populations. Verticillium samples from lettuce comprised 163 isolates from three fields (Harkins $=32$, sampled in 2009, and Cooper $1=84$ and Cooper $2=47$, sampled in 2010) in Salinas (Fig. 1). Verticillium samples from tomato comprised 43 isolates from a single field in Yolo County, sampled in 2012. All isolates were confirmed to be $V$. dahliae from Verticillium spp.-specific PCR. All lettuce isolates and all except one tomato isolate (Le1806) were MAT1-2-1. All field lettuce isolates also amplified with effectorspecific Ave1 PCR, indicating that they were race 1, but no tomato isolates amplified with the Ave1 PCR. Putative race 2-specific primers amplified DNA from the majority of tomato isolates but none from lettuce isolates.

Population genetics analyses of isolates from disease nursery. Genetic diversity. All 427 isolates collected from the disease nursery were genotyped with 13 SSR markers, as previously described. With the exception of four SSR loci (VD1, VD8, VD10, and VD7), all SSR generated monomorphic alleles identical to the reference isolate Ls16 that was originally introduced into the field. At the polymorphic SSR loci, two, three, two, and two alleles were detected, respectively. In total, 18 alleles were observed at 13 SSR loci, resulting in six distinct MLG (Fig. 2A). In all, 420 isolates $(98.36 \%)$ belonged to a single locus genotype (MLG.1). MLG.3, 4, and 6 were singletons collected in 2012, 2015, and 2012, respectively. MLG. 2 consisted of two isolates from fall 2013 and MLG.5 consisted of two isolates, one from spring 2013 and one from fall 2015.

Population structure and index of association. For V. dahliae samples collected from the disease nursery, no significant population differentiation $(\Phi p t=0.012, P=0.245)$ was observed among collection years (Table 1, A). The standardized index of association $(r B a r D)$ test further indicated a significant multilocus linkage disequilibrium on all populations combined over the years, supporting the hypothesis of a clonal population in the field nursery.

Identification of mutant genotypes in the disease nursery. All isolates having at least one allele distinct from the alleles in genome
Ls16 were classified as mutant genotypes. Seven isolates (Ls2936, Ls2938, Ls3243, Ls3246, Ls3355, Ls3364, and Ls3662) were identified as mutant genotypes due to either a gain or loss of at least one SSR repeat motif in 1 of the 13 SSR loci used (Table 2).

Sequencing the mutant loci revealed a 30 -bp deletion (10 copies of motif GAT) in locus VD8 for isolate Ls3246 and a 6-bp insertion (one copy of motif CGTTGC in VD73) in isolates Ls3243 and Ls3662 relative to the wild-type Ls16, respectively (Table 2; Fig. 3). The remaining four mutants either lost or gained a single motif (Table 2). In addition to SSR variation, three single-nucleotide polymorphisms were detected in locus VD73 compared with the reference genome sequence of isolate Ls 17 from which primers were designed (Fig. 3).

Race structure and pathogenicity of mutant genotypes. The lettuce plants from which mutant isolates were recovered showed symptoms of outer wilted leaves and vascular taproot discoloration in the disease nursery. The genotype Honcho II had the lowest disease severity $(<2)$ followed by the genotypes Green Lightning, RH12-1633, Salad Crisp, and RH12-1586, with disease rating scores of 2 or 3. The genotypes Quest MT and Salinas were the most susceptible and received the highest disease rating scores of 4 to 5 (Table 2). At least one mutant genotype was recovered from both these genotypes over the years.

Inoculation of mutant isolates in two host differentials indicated that all mutants were pathogenic on susceptible Salinas lettuce but nonpathogenic on resistant La Brillante (Table 2; Fig. 4A), demonstrating that these mutants still carried a functional Avel homolog. No V. dahliae was recovered from plating symptomless La Brillante taproots on NP-10 media, indicating lack of latent infection as well. Inoculation of the highly susceptible Long Purple eggplant with isolates Ls16, Ls3243, and Ls3246 all resulted in severe disease symptoms, including severe stunting and vascular discoloration in the tap root (Fig. 4B).

Population genetics analyses of isolates from the field. Simple sequence repeat diversity. In total, 37 alleles from 163 lettuce isolates and 34 alleles from 43 tomato isolates were generated by the 13 microsatellite loci. The SSR loci VD1 and VD11 in lettuce isolates and VD9 and VD92 in tomato isolates were monomorphic, whereas the remaining $11(84.61 \%)$ markers were polymorphic in each populations. In total, 30 and 21 MLG were identified in $V$. dahliae populations sampled from lettuce and tomato, respectively. In all, 99

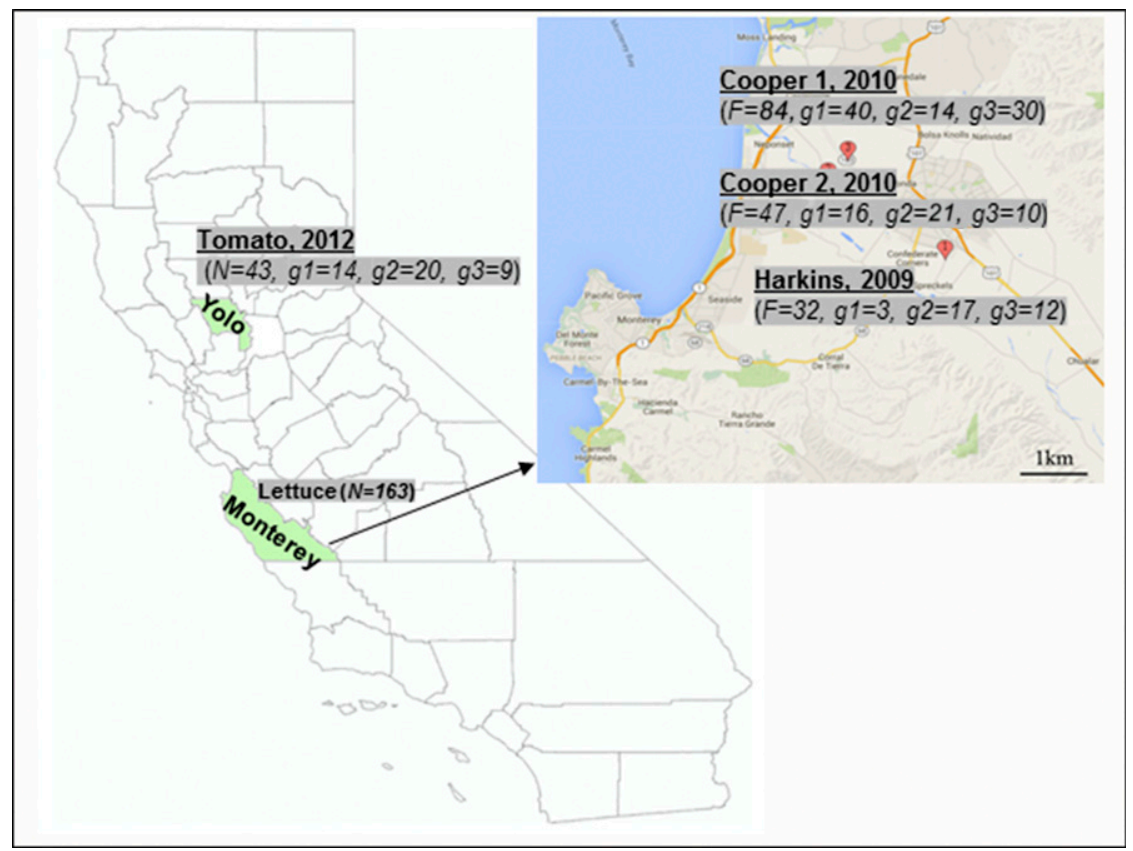

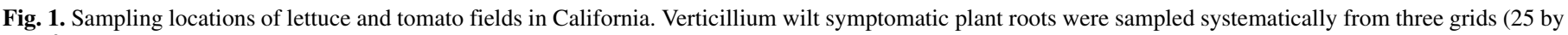

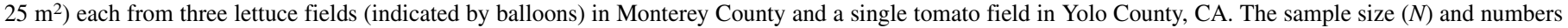
of isolates collected from each field $(F)$ and grids $(g)$ are indicated in parentheses. 
$(60.73 \%)$ isolates from lettuce and $13(30.23 \%)$ isolates from tomato belonged to a single MLG, while 20 and 18 MLG singleton genotypes were identified from lettuce and tomato, respectively (Fig. 2B and C). Among lettuce fields, Cooper2 had the highest clonal fraction (0.83) followed by Harkins (0.75) and Copper $1(0.70)$; the clonal fraction of lettuce isolates from all fields was 0.82 . The clonal fraction of tomato isolates was 0.51 (Table 3). No genotypes were shared between the population samples from the two hosts.

The measure of Nei's average overall gene diversity $(H)$ was similar in $V$. dahliae populations from lettuce $(0.247)$ and tomato

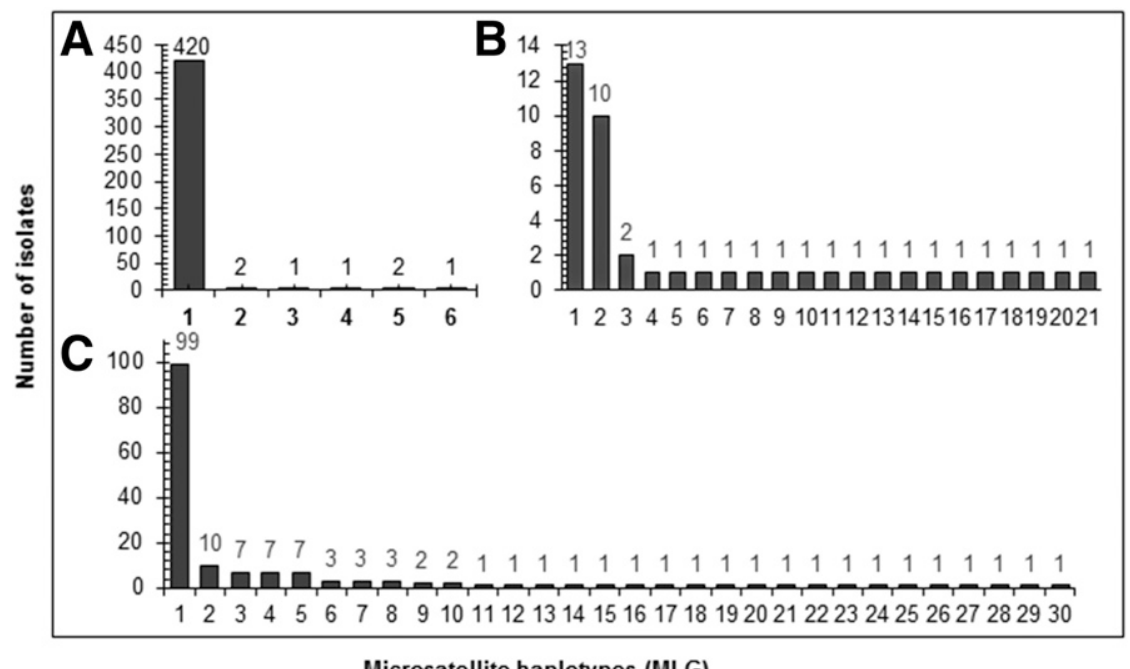

Fig. 2. Histograms of multilocus genotype frequency of Verticillium dahliae in A, race 1 disease nursery; $\mathbf{B}$, tomato field; and $\mathbf{C}$, combined isolates from three lettuce fields.

TABLE 1. Analysis of molecular variance of Verticillium dahliae populations sampled at the race 1 disease nursery $(N=427)$, lettuce $(N=163)$, and tomato $(N=43)$ fields

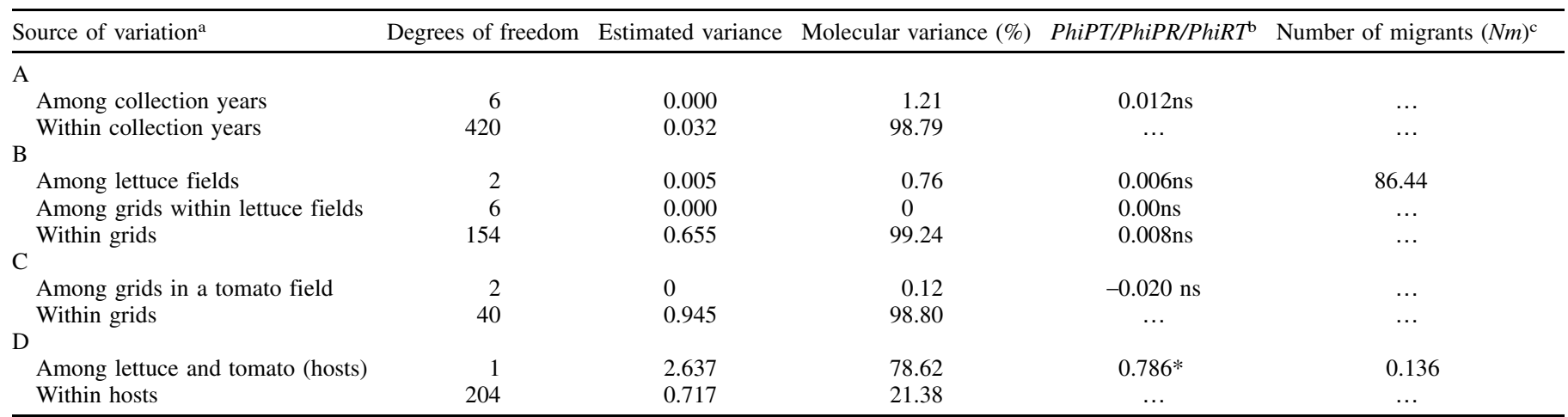

${ }^{a}$ Variances were partitioned as follows: A, within and among population based on sampling years in race 1 disease nursery; B, between three lettuce fields and between and within nine grids in lettuce; $\mathrm{C}$, among grids in tomato; and $\mathrm{D}$, between lettuce and tomato.

b PhiPT, PhiPR, and PhiRT are the distributions of variation among populations, fields, and populations within fields, respectively; ns $=$ not significant at $P<0.05$ and $*$ significant at $P=0.001$.

${ }^{\mathrm{c}}$ Haploid number of migrant genotypes $\left(N_{m}\right)$ was calculated using $N_{m}=\left[\left(1 / \phi_{\mathrm{PT}}\right)-1\right] / 2$ using GeneAlex 5.2.

TABLE 2. Single-locus mutant genotypes of Verticillium dahliae isolates sampled from a race 1 disease nursery during 2012 to 2015

\begin{tabular}{|c|c|c|c|c|c|c|c|c|c|c|c|}
\hline \multirow[b]{2}{*}{ Isolate } & \multirow[b]{2}{*}{ Year } & \multirow[b]{2}{*}{ Cultivar } & \multirow[b]{2}{*}{ Score $^{\mathrm{c}}$} & \multirow[b]{2}{*}{ Race } & \multirow[b]{2}{*}{ MAT $^{d}$} & \multicolumn{4}{|c|}{$\mathrm{SSR}^{\mathrm{a}}$} & \multicolumn{2}{|c|}{ Severity ${ }^{b}$} \\
\hline & & & & & & Vd1 & Vd73 & $\mathrm{Vd} 8$ & Vd10 & Sal & $\mathrm{LaB}$ \\
\hline Ls16 & & Salinas & 5 & 1 & MAT1-2-1 & 299 & 289 & 401 & 254 & 5 & 0 \\
\hline Ls2936 & 2012 & Honcho II & 1.4 & 1 & MAT1-2-1 & 299 & 289 & 398 & 254 & 4 & 0 \\
\hline Ls3355 & 2013 fall & RH12-1633 & 3.0 & 1 & MAT1-2-1 & 299 & 289 & 401 & 250 & 4 & 0 \\
\hline Ls3662 & 2013 spring & Salad Crisp & 3.0 & 1 & MAT1-2-1 & 299 & 295 & 401 & 254 & 4.5 & 0 \\
\hline Ls3364 & 2013 fall & RH12-1586 & 3.0 & 1 & MAT1-2-1 & 299 & 289 & 401 & 250 & 5 & 0 \\
\hline
\end{tabular}

a Simple sequence repeat (SSR) locus and alleles (polymerase chain reaction amplicon size).

b Median disease severity for Salinas $(\mathrm{Sal})$ and La Brillante $(\mathrm{LaB})$ lettuce from 30 plants across three replications was evaluated at 10 weeks after inoculation based on vascular discoloration using disease score of 0 to 5 .

${ }^{c}$ Disease ratings were assigned at the time of sampling based on vascular discoloration using an ordinal scale (0 to 5), as described by (Hayes et al. 2011c). Scores were an average of 10 plants in a row per cultivar.

${ }^{\mathrm{d}}$ Mating type. 
(0.228) (Table 3). The diversity within subpopulations in lettuce grids varied from 0.086 to 0.244 and in tomato grids from 0.169 to 0.218 . The grid subpopulations $\mathrm{C} 1 \mathrm{G} 3, \mathrm{C} 2 \mathrm{G} 1$, and $\mathrm{C} 2 \mathrm{G} 3$ had higher gene diversity than other grid subpopulations (Table 3). Within lettuce, the Harkins subpopulations were less diverse than others.

Population structure and index of association. The AMOVA indicated no significant differentiation within field populations of either lettuce or tomato (Table 1, B and C). In addition, the nine grid subpopulations (C1G1, C1G2, C1G3, C2G1, C2G2, C2G3, HG1, $\mathrm{HG} 2$, and HG3) and three lettuce field populations (Cooper1, Cooper2, and Harkins) had very low genetic variation $(0.76 \%)$ due to differences between grid subpopulations, whereas $>99 \%$ of variation was attributed due to genotypic differences among individuals within grid subpopulations (Table 1, B and C). Similarly, the tomato grid subpopulations (YG1, YG2, and YG3) had very low variation $(0.12 \%)$ within a population but exhibited a very high variation $(98.8 \%)$ among individuals within the population. Estimates of the overall haploid number of migrants $(\mathrm{Nm})$ among lettuce fields was high $(\mathrm{Nm}=86.44)$. However, AMOVA indicated a strong evidence for very high genotypic variation (78.62\%) due to differences between lettuce and tomato populations but only $21.38 \%$ of variation from individuals within a population. V. dahliae populations collected from these two hosts (lettuce and tomato) were significantly differentiated $(P h i P T=0.786, P=0.001)$, with a very low estimated number of migrant genotypes $(\mathrm{Nm}=0.136)$ (Table 1D).

The PCA using NTSYSpc further delineated tomato and lettuce genotypes into two distinct clusters correlating with the host of origin. In total, 54 alleles generated by 13 markers among 206 isolates were used for cluster analysis. Dimension one of the PCA (eigenvalue $=28.54)$ distinctly separated isolates based on host origin (Fig. 5).

The standardized index of association $(r B a r D)$ was only calculated for lettuce fields and between two host populations, not for individual grid subpopulations, due to the very low number of isolates in each grid subpopulation remaining after clone correction. Populations of $V$. dahliae within and between lettuce and tomato fields indicated significant linkage disequilibrium $(r B a r D=0.028$ to $0.302, P<0.05$ ) (Table 3 ). All of the populations analyzed indicated a significant linkage disequilibrium, as expected in asexually reproducing clonal populations. No evidence of recombination was detected within or between the two host populations.

\section{DISCUSSION}

Verticillium wilt of lettuce in Salinas and the surrounding valleys has become more prevalent since its first emergence during the mid1990s (Subbarao et al. 1997; Vallad et al. 2006). Although lettuce is infected by two pathogenic races of $V$. dahliae, race 1 has been recovered in opportunistic collections of isolates far more frequently since 1995 than race 2 (Gurung et al. 2014). We investigated whether lettuce crops with a mosaic of genotypes with different levels of resistance would impose a detectable selection pressure over 6 years to potentially alter its virulence or lead to the emergence of mutants that lack Avel. Lettuce material planted each season consisted of early- and intermediate-generation families and inbred lines derived from crosses to incorporate race 1 resistance from $\mathrm{La}$ Brillante (race 1 resistant, $V r l$ ) and other cultivars of iceberg, romaine, and leaf-type lettuce. All isolates recovered over the 6-year period were $V$. dahliae race 1 . Assuming a similar selection pressure after deployment of $V r l$ genotypes into commercial fields, and that no novel pathogen genotypes or races are introduced into the production system (Short et al. 2015a), our results suggest that $\mathrm{Vrl}$ will remain effective against the race 1 populations that are currently commonplace in field soils for at least 6 years. However, widespread deployment of $\mathrm{Vrl}$ resistance in lettuce monocrops could impose stronger selection pressure than that encountered in this experiment.

Seven SSR mutant isolates and five novel alleles different from the parental Ls16 allelic profile were identified from the disease nursery over 6 years. The microsatellites are generally highly polymorphic in

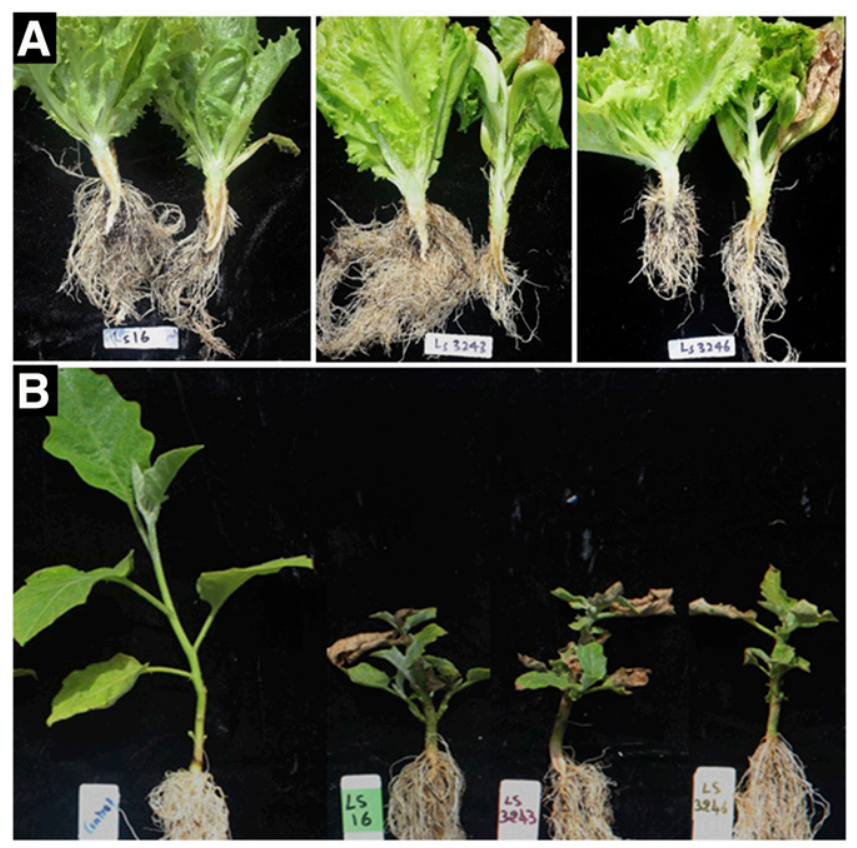

Fig. 4. Inoculation test of simple sequence repeat (SSR) mutant genotypes on lettuce differential and a susceptible eggplant cultivar. Two representative mutants (Ls3243 and Ls3246) were used to inoculate A, Verticillium dahliae race 1-resistant La Brillante (top: left photo of each isolate) and $\mathbf{B}$, susceptible Salinas (top: right photo of each isolate) lettuce and $\mathbf{B}$, Long Purple eggplant (bottom, left to right: mock, wild-type, and mutant inoculated).

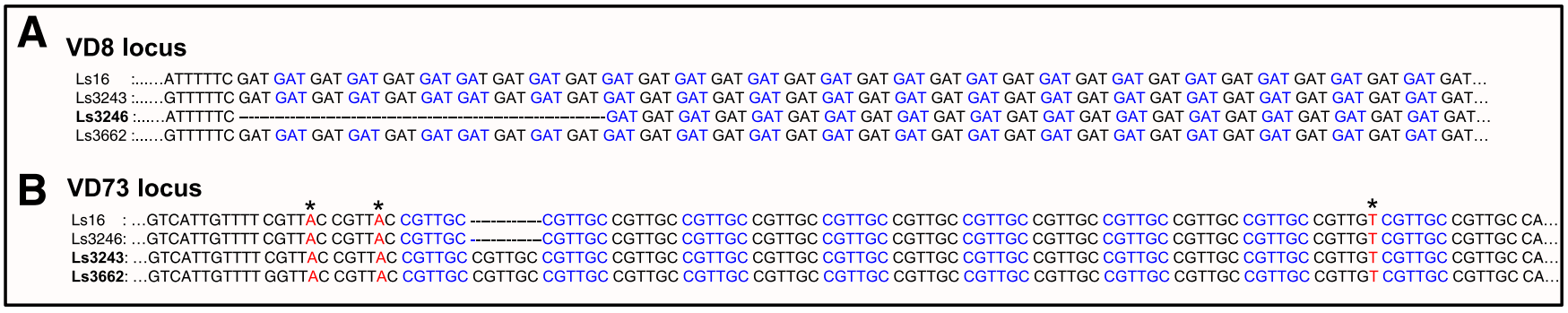

Nucleotide sequences of SSR loci

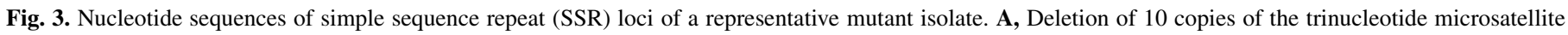

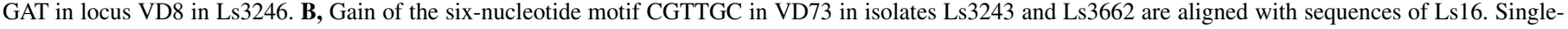
nucleotide polymorphisms are indicated by an asterisk. 
V. dahliae (Short et al. 2015b). Thus, in the current study, we used them to investigate the evolutionary potential of a single clonal lineage of $V$. dahliae. In general, the mutation rates of SSR loci are higher than other genomic regions (Ellegren 2004), which varies and positively correlates to the number of nucleotide repeat units in each motif (Weber and Wong 1993). Of the total 13 SSR, the markers VD8 (motif size 3 bp), VD10 (motif size 4 bp), and VD73 (motif size $6 \mathrm{bp}$ ) appeared relatively more mutable than others. Distinct alleles were rare and were recovered beginning the third year of sampling. These observations provide direct evidence of the molecular evolution of this soilborne plant pathogen.

The lack of significant variation in virulence of the seven mutant isolates relative to the parental isolate further suggested that the mutations were not associated with functional changes to Ave1 or other pathogenicity-related genes. Comparative genomic analyses of Verticillium spp. have suggested that Ave1 was acquired by race 1 or lost in race 2 isolates in $V$. dahliae several times during evolution (de Jonge et al. 2013). Similarly, the loss or exchange of effector genes has been documented in the Avr-Pita gene family in Magnaporthe oryzae (Chuma et al. 2011). Thus, the data provide evidence that a single race 1 clonal population would need longer than 6 years to overcome $\mathrm{Vrl}$-mediated resistance through somatic mutations.

We further evaluated the population dynamics of $V$. dahliae isolates sampled within and between commercial lettuce and tomato fields. The lettuce-associated $V$. dahliae genotypes used in the current study were published previously (Gurung et al. 2014) but were used here to compare inter- and intrafield population diversity. Significant linkage disequilibrium among fields confirmed that clonal, asexually reproducing populations of $V$. dahliae exist in both lettuce and tomato, consistent with previous reports (ColladoRomero et al. 2006; Gurung et al. 2014; Milgroom et al. 2014). Similar patterns of clonality have been reported in heterothallic Phytophthora spp. (Vercauteren et al. 2010) and homothallic, plantpathogenic Fusarium spp. (Karugia et al. 2009; Puri et al. 2012) from disease nurseries or a single field. Gurung et al. (2014) highlighted a diverse sample of $V$. dahliae on susceptible lettuce cultivars $(v r l)$ in 48 lettuce fields sampled in Salinas and Watsonville over the 18 years of isolate collections (1995 to 2012) that were dominated by a small number of multilocus haplotypes within the race 1 genotype. The continuous recovery of dominant clones indicated that, under field conditions, these race 1 genotypes appear to be highly adapted to Salinas Valley soils that routinely reproduce on susceptible ( $v r l$ ) lettuce cultivars. This suggests that $V r l$ will likely remain effective for at least 6 years against the $V$. dahliae race 1 isolate that predominates in the Salinas Valley, unless novel races are introduced into the system. The $V r l$ gene is also effective against isolates of $V$. isaacii and V. klebahnii from artichoke, lettuce, and spinach (Gurung et al. 2015). However, Gurung et al. (2014) reported the existence of a few race 2 isolates in Salinas, Monterey County, and Watsonville, Santa Cruz County, though none of these fields were predominantly or exclusively infested with race 2 . The $V$. dahliae race 2 reference isolate Ls 17 readily forms microsclerotia (soil survival structures) in culture and is highly virulent on $v r l$ Salinas and $\mathrm{Vrl} \mathrm{La}$ Brillante lettuce. However, repeated efforts to establish a race 2 disease nursery using race 2 isolate Ls 17 for several years was unsuccessful (K. V. Subbarao, unpublished). Thus, race 2 isolates associated with

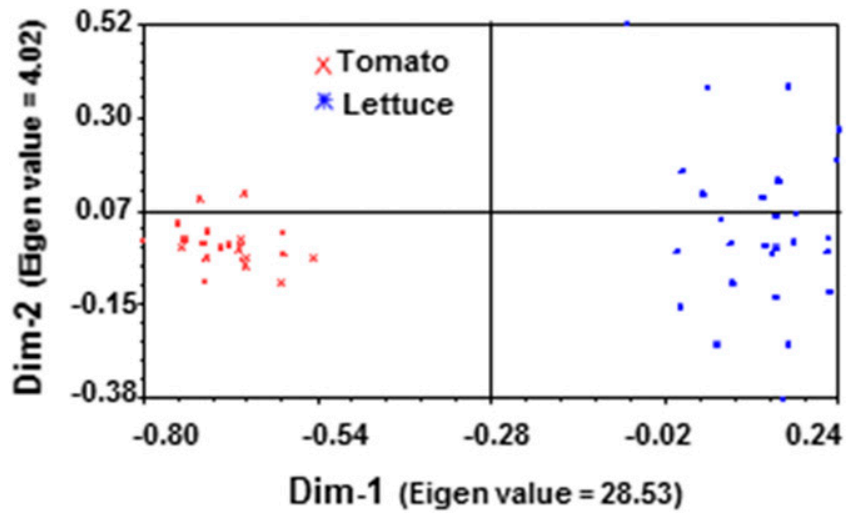

Fig. 5. Principal component analysis of 206 Verticillium dahliae isolates from lettuce and tomato. In total, 54 alleles generated by 13 SSR markers were analyzed using NTSYSpc on a similarity matrix using DECENTER and EIGEN functions.

TABLE 3. Basic population genetic statistics of Verticillium dahliae sampled from three lettuce fields in Salinas, CA and a tomato field in Yolo County, CA

\begin{tabular}{|c|c|c|c|c|c|c|}
\hline Crop, field location, population & Sample size & Clone corrected & Clonal fraction $^{\mathrm{a}}$ & Polymorphic loci (\%) & Gene diversity $(H)^{\mathrm{b}}$ & $r B a r D^{c}$ \\
\hline \multicolumn{7}{|l|}{ Lettuce } \\
\hline \multicolumn{7}{|l|}{ Cooper 1} \\
\hline Grid 1 (C1G1) & 40 & 13 & 0.68 & 61.54 & 0.194 & - \\
\hline Grid 3 (C1G3) & 30 & 11 & 0.63 & 69.23 & 0.239 & - \\
\hline Cooper 1 & 84 & 25 & 0.70 & $\ldots$ & 0.213 & $0.0396 * *$ \\
\hline \multicolumn{7}{|l|}{ Cooper 2} \\
\hline Grid 1 (C2G1) & 16 & 4 & 0.75 & 46.15 & 0.244 & - \\
\hline Cooper 2 & 47 & 8 & 0.83 & $\ldots$ & 0.234 & $0.1867 * *$ \\
\hline \multicolumn{7}{|l|}{ Harkins } \\
\hline Grid 1 (HG1) & 3 & 3 & 0.00 & 23.08 & 0.154 & - \\
\hline Grid 2 (HG2) & 17 & 4 & 0.76 & 53.85 & 0.100 & - \\
\hline Grid 2 (HG3) & 12 & 5 & 0.58 & 23.08 & 0.086 & - \\
\hline Harkins & 32 & 8 & 0.75 & 84.61 & 0.236 & $0.2040 * *$ \\
\hline Lettuce combined & 163 & 30 & 0.82 & $\ldots$ & 0.247 & $0.0853 * *$ \\
\hline Grid 2 (YG3) & 9 & 5 & 0.44 & 38.46 & 0.169 & - \\
\hline Tomato combined & 43 & 21 & 0.51 & 84.61 & 0.228 & $0.0280 *$ \\
\hline Lettuce and tomato & 206 & 51 & 0.75 & $\ldots$ & 0.401 & $0.3022 * *$ \\
\hline
\end{tabular}

a Clonal fraction was measured as 1 - [(number of different genotypes)/(total number of isolates)] (Zhan et al. 2002).

b Nei's unbiased gene diversity (Nei 1978) within populations was calculated on clone-corrected data using Poppr (Kamvar et al. 2014).

c Standardized indices of association (rBarD) were estimated for each population (Agapow and Burt 2001) using the R package Poppr (Kamvar et al. 2014). The significance of $r$ BarD estimations were computed with 1,000 randomizations. The null hypothesis of multilocus linkage equilibrium was tested and rejected if $P<0.05 ; *$ and $* *=$ significant at $P=0.05$ and 0.001 , respectively, and $-=$ not calculated to grid level due to low sample size. 
Salinas Valley lettuce might be less fit in field environments and may turn out to be less of a concern post-Vrl deployment. Based on the apparent lower fitness of the currently prevalent race 2 populations in field conditions, the resistance offered by the $V r l$ gene may remain effective and serve as a robust source of Verticillium wilt resistance, in contrast to what occurred following Vel deployment in tomato cultivars (Alexander 1962; Grogan et al. 1979). Notably, imported spinach seed lots, which have been documented to harbor a high diversity of $V$. dahliae isolates (Short et al. 2015a), may represent an important source of inoculum for variants of $V$. dahliae. Together with the recently reported third race (Usami et al. 2016) in tomato that is likely to also occur in lettuce, the highly fit race 2 strains introduced by infested spinach seed in the future may reduce the durability of $\mathrm{Vrl}$.

Isolates from commercial lettuce fields in Monterey County and a commercial tomato field in Yolo County (approximately $300 \mathrm{~km}$ apart) revealed significant population differentiation, as reported previously (Atallah et al. 2010). Estimates of gene flow were low between hosts and race structure was also distinct: lettuce fields harbored primarily $V$. dahliae race 1 isolates while the tomato field harbored $V$. dahliae race 2 isolates. The widespread commercial use of the Vel gene in tomato cultivars replaced the race 1 isolates within 10 years in the 1950 s, with race 2 becoming a problem in Ohio (Alexander 1962) and California (Grogan et al. 1979) in the United States; Ontario, Canada (Dobinson et al. 1996); and European countries (Pegg 1974). A race 2 population present in the tomato fields at a low frequency was subjected to selection pressure by race 1 resistant cultivars (Dobinson et al. 1996), leading to its widespread establishment. It is unknown whether the $V r l$ lettuce system will lead to a similar situation.

The presence of a single MAT1-1 isolate (2.3\% of total isolates) out of 43 isolates in the tomato field raises questions regarding the occurrence of sexuality in these fields. No sexual stage is known to exist in $V$. dahliae, despite the maintenance of sex-related genes in the genome, and the existence of clonal lineages that appear to have arisen due to recombination (Milgroom et al. 2014; Short et al. 2014a). Several mechanisms of asexual molecular evolution have been posited, including horizontal gene transfer, chromosomal rearrangements (intra- and interchromosomal), and transposable elements, all of which may generate variation upon which selection can act (de Jonge et al. 2013; Seidl and Thomma 2014). Amyotte et al. (2012) identified nonrandom insertions of transposable elements that contributed to the generation of four lineage-specific (LS) regions enriched for pathogenicity-related genes in the genome on race 2 isolate-Ls17, and the unique LysM effector (Kombrink et al. 2017).

Thus, a strictly monoclonal race 1 population of $V$. dahliae established in a disease nursery was exposed to selection pressure of $V r 1$ in different genetic backgrounds and yet it did not result in the loss of Ave1. Consistent with a model of clonal expansion, the field populations of $V$. dahliae in lettuce and tomato were dominated by a single MLG with a few other rare genotypes, whereas populations were distinct between these hosts. Based on these results, a strong quarantine measure that prevents the direct movement of inoculum or inoculum sources is warranted and will help maintain the efficacy and durability of race 1 resistance in lettuce.

\section{ACKNOWLEDGMENTS}

We thank R. Marchebout and L. C. Landeros for their excellent technical assistance in the greenhouse and field experiments. A portion of this research was funded by USDA National Institute for Food and Agriculture (NIFA) grant number 59-5305-4-002 and USDA-NIFA Specialty Crops Research Initiative grant number 2010-51181-21069 as well as annual funding from the California Leafy Greens Research Board.

\section{LITERATURE CITED}

Agapow, P. M., and Burt, A. 2001. Indices of multilocus linkage disequilibrium. Mol. Ecol. Notes 1:101-102.

Agrios, G. N. 2005. Plant Pathology. Academic Press, San Diego, CA.
Alexander, L. J. 1962. Susceptibility of certain Verticillium resistant tomato varieties to an Ohio isolate of the fungus. Phytopathology 52:998-1000.

Almany, G. R., De Arruda, M. P., Arthofer, W., Atallah, Z. K., Beissinger, S. R., Berumen, M. L., Bogdanowicz, S. M., Brown, S. D., Bruford, M. W., Burdine, C., Busch, J. W., Campbell, N. R., Carey, D., Carstens, B. C., Chu, K. H., Cubeta, M. A., Cuda, J. P., Cui, Z., Datnoff, L. E., Dávila, J. A., Davis, E. S., Davis, R. M., Diekmann, O. E., Eizirik, E., Fargallo, J. A., Fernandes, F., Fukuda, H., Gale, L. R., Gallagher, E., Gao, Y., Girard, P., Godhe, A., Gonçalves, E. C., Gouveia, L., Grajczyk, A. M., Grose, M. J., Gu, Z., Halldén, C., Härnström, K., Hemmingsen, A. H., Holmes, G., Huang, C. H., Huang, C.-C., Hudman, S. P., Jones, G. P., Kanetis, L., Karunasagar, I., Karunasagar, I., Keyghobadi, N., Klosterman, S. J., Klug, P. E., Koch, J., Koopman, M. M., Köppler, K., Koshimizu, E., Krumböck, S., Kubisiak, T., Landis, J. B., Lasta, M. L., Lee, C.-Y., Li, Q., Li, S.-H., Lin, R.-C., Liu, M., Liu, N. A., Liu, W. C., Liu, Y., Loiseau, A., Luan, W., Maruthachalam, K. K., McCormick, H. M., Mellick, R., Monnahan, P. J., Morielle-Versute, E., Murray, T. E., Narum, S. R., Neufeld, K., De Nova, P. J. G., Ojiambo, P. S., Okamoto, N., Othman, A. S., Overholt, W. A., Pardini, R., Paterson, I. G., Patty, O. A., Paxton, R. J., Planes, S., Porter, C., Pratchett, M. S., Püttker, T., Rasic, G., Rasool, B., Rey, O., Riegler, M., Riehl, C., Roberts, J. M. K., Roberts, P. D., Rochel, E., Roe, K. J., Rossetto, M., Ruzzante, D. E., Sakamoto, T., Saravanan, V., Sarturi, C. R., Schmidt, A., Schneider, M. P. C., Schuler, H., Serb, J. M., Serrão, E. T. A., Shi, Y., Silva, A., Sin, Y. W., Sommer, S., Stauffer, C., Strüssmann, C. A., Subbarao, K. V., Syms, C., Tan, F., Tejedor, E. D., Thorrold, S. R., Trigiano, R. N., Trucco, M. I., Tsuchiya-Jerep, M. T. N., Vergara, P., Van De Vliet, M. S., Wadl, P. A., Wang, A., Wang, H., Wang, R. X., Wang, X., Wang, Y. A. N., Weeks, A. R., Wei, F., Werner, W. J., Wiley, E. O., Williams, D. A., Wilkins, R. J., Wisely, S. M., With, K. A., Wu, D., Yao, C.-T., Yau, C., Yeap, B.-K., Zhai, B.-P., Zhan, X., Zhang, G.-Y., Zhang, S. Y., Zhao, R. U., and Zhu, L. 2009. Permanent genetic resources added to Molecular Ecology Resources Database 1 May 2009-31 July 2009. Mol. Ecol. Resour. 9: 1460-1466.

Amyotte, S. G., Tan, X. P., Pennerman, K., Jimenez-Gasco, M. D., Klosterman, S. J., Ma, L. J., Dobinson, K. F., and Veronese, P. 2012. Transposable elements in phytopathogenic Verticillium spp.: Insights into genome evolution and inter- and intra-specific diversification. BMC Genomics 13:314.

Atallah, Z. K., Hayes, R. J., and Subbarao, K. V. 2011. Fifteen years of Verticillium wilt of lettuce in America's salad bowl: A tale of immigration, subjugation, and abatement. Plant Dis. 95:784-792.

Atallah, Z. K., Maruthachalam, K., du Toit, L., Koike, S. T., Davis, R. M., Klosterman, S. J., Hayes, R. J., and Subbarao, K. V. 2010. Population analyses of the vascular plant pathogen Verticillium dahliae detect recombination and transcontinental gene flow. Fungal Genet. Biol. 47: 416-422.

Bhat, R. G., and Subbarao, K. V. 1999. Host range specificity in Verticillium dahliae. Phytopathology 89:1218-1225.

Castroverde, C. D., Nazar, R. N., and Robb, J. 2016. Verticillium Ave1 effector induces tomato defense gene expression independent of Ve1 protein. Plant Signal. Behav. 11:e1245254.

Chellemi, D. O., Gamliel, A., Katan, J., and Subbarao, K. V. 2016. Development and deployment of systems-based approaches for the management of soilborne plant pathogens. Phytopathology 106:216-225.

Chen, T., Kan, J., Yang, Y., Ling, X., Chang, Y., and Zhang, B. 2016. A Ve homologous gene from Gossypium barbadense, Gbvdr3, enhances the defense response against Verticillium dahliae. Plant Physiol. Biochem. 98: 101-111.

Chuma, I., Isobe, C., Hotta, Y., Ibaragi, K., Futamata, N., Kusaba, M., Yoshida, K., Terauchi, R., Fujita, Y., Nakayashiki, H., Valent, B., and Tosa, Y. 2011. Multiple translocation of the AVR-Pita effector gene among chromosomes of the rice blast fungus Magnaporthe oryzae and related species. PLoS Pathog.7:e1002147.

Cirulli, M., Bubici, G., Amenduni, M., Armengol, J., Berbegal, M., Jiménez-Gasco, M. M., and Jiménez-Díaz, R. M. 2010. Verticillium wilt: A threat to artichoke production. Plant Dis. 94:1176-1187.

Collado-Romero, M., Mercado-Blanco, J., Olivares-García, C., Valverde-Corredor, A., and Jiménez-Díaz, R. M. 2006. Molecular variability within and among Verticillium dahliae vegetative compatibility groups determined by fluorescent amplified fragment length polymorphism and polymerase chain reaction markers. Phytopathology 96:485-495.

Cowger, C., Hoffer, M. E., and Mundt, C. C. 2000. Specific adaptation by Mycosphaerella graminicola to a resistant wheat cultivar. Plant Pathol. 49: 445-451.

de Jonge, R., Bolton, M. D., Kombrink, A., van den Berg, G. C. M., Yadeta, K. A., and Thomma, B. P. H. J. 2013. Extensive chromosomal reshuffling drives evolution of virulence in an asexual pathogen. Genet. Res. 23:1271-1282.

de Jonge, R., van Esse, H. P., Maruthachalam, K., Bolton, M. D., Santhanam, P., Saber, M. K., Zhang, Z., Usami, T., Lievens, B., Subbarao, K. V., and 
Thomma, B. P. 2012. Tomato immune receptor Ve1 recognizes effector of multiple fungal pathogens uncovered by genome and RNA sequencing. Proc. Natl. Acad. Sci. USA 109:5110-5115.

Dobinson, K., Tenuta, G., and Lazarovits, G. 1996. Occurrence of race 2 of Verticillium dahliae in processing tomato fields in southwestern Ontario. Can. J. Plant Pathol. 18:55-58.

Douhan, L. I., and Johnson, D. A. 2001. Vegetative compatibility and pathogenicity of Verticillium dahliae from spearmint and peppermint. Plant Dis. 85:297-302.

Ellegren, H. 2004. Microsatellites: Simple sequences with complex evolution. Nat. Rev. Genet. 5:435-445.

Gossmann, T. I., Keightley, P. D., and Eyre-Walker, A. 2012. The effect of variation in the effective population size on the rate of adaptive molecular evolution in eukaryotes. Genome Biol. Evol. 4:658-667.

Grogan, R. G., Ioannou, N., Schneider, R. W., Sall, M. A., and Kimble, K. A. 1979. Verticillium wilt on resistant tomato cultivars in California: Virulence of isolates from plants and soil and relationship of inoculum density to disease incidence. Phytopathology 69:1176-1180.

Gurung, S., Short, D. P., Atallah, Z. K., and Subbarao, K. V. 2014. Clonal expansion of Verticillium dahliae in lettuce. Phytopathology 104:641-649.

Gurung, S., Short, D. P. G., Hu, X., Sandoya, G. V., Hayes, R. J., Koike, S. T., and Subbarao, K. V. 2015. Host range of Verticillium isaacii and Verticillium klebahnii from artichoke, spinach, and lettuce. Plant Dis. 99:933-938.

Hayes, R. J., Maruthachalam, K., Vallad, G. E., Klosterman, S. J., Simko, I., Luo, Y., and Subbarao, K. V. 2011a. Iceberg lettuce breeding lines with resistance to Verticillium wilt caused by race 1 isolates of Verticillium dahliae. HortScience 46:501-504.

Hayes, R. J., Maruthachalam, K., Vallad, G. E., Klosterman, S. J., and Subbarao, K. V. 2011b. Selection for resistance to Verticillium wilt caused by race 2 Isolates of Verticillium dahliae in accessions of lettuce (Lactuca sativa L.). HortScience 46:201-206.

Hayes, R. J., McHale, L. K., Vallad, G. E., Truco, M. J., Michelmore, R. W., Klosterman, S. J., Maruthachalam, K., and Subbarao, K. V. 2011c. The inheritance of resistance to Verticillium wilt caused by race 1 isolates of Verticillium dahliae in the lettuce cultivar La Brillante. Theor. Appl. Genet. 123:509-517.

Hayes, R. J., Vallad, G. E., Qin, Q.-M., Grube, R. C., and Subbarao, K. V. 2007. Variation for Resistance to Verticillium wilt in lettuce (Lactuca sativa L.). Plant Dis. 91:439-445.

Iglesias-Garcia, A. M., Villarroel-Zeballos, M. I., Feng, C. D., du Toit, L. J., and Correll, J. C. 2013. Pathogenicity, virulence, and vegetative compatibility grouping of Verticillium isolates from spinach seed. Plant Dis. 97: 1457-1469.

Inderbitzin, P., Bostock, R. M., Davis, R. M., Usami, T., Platt, H. W., and Subbarao, K. V. 2011. Phylogenetics and taxonomy of the fungal vascular wilt pathogen Verticillium, with the descriptions of five new species. PLoS One 6:e28341

Inderbitzin, P., Davis, R. M., Bostock, R. M., and Subbarao, K. V. 2013. Identification and differentiation of species and sineages by simplex and multiplex PCR assays. PLoS One 8:e65990.

Kabir, Z., Bhat, R. G., and Subbarao, K. V. 2004. Comparison of media for recovery of Verticillium dahliae from soil. Plant Dis. 88:49-55.

Kamvar, Z. N., Tabima, J. F., and Grunwald, N. J. 2014. Poppr: An R package for genetic analysis of populations with clonal, partially clonal, and/or sexual reproduction. PeerJ 2:e281.

Karugia, G. W., Suga, H., Gale, L. R., Nakajima, T., Tomimura, K., and Hyakumachi, M. 2009. Population structure of the Fusarium graminearum species complex from a single Japanese wheat field sampled in two consecutive years. Plant Dis. 93:170-174.

Koike, S. T., Subbarao, K. V., Davis, R. M., Gordon, T. R., and Hubbard, J. C. 1994. Verticillium wilt of cauliflower in California. Plant Dis. 78:1116-1121.

Kombrink, A., Rovenich, H., Shi-Kunne, X., Rojas-Padilla, E., van den Berg, G. C. M., Domazakis, E., de Jonge, R., Valkenburg, D.-J., Sánchez-Vallet, A., Seidl, M. F., and Thomma, B. P. H. J. 2017. Verticillium dahliae LysM effectors differentially contribute to virulence on plant hosts. Mol. Plant Pathol. 18:596-608.

Leach, J. E., Vera Cruz, C. M., Bai, J., and Leung, H. 2001. Pathogen fitness penalty as a predictor of durability of disease resistance genes. Annu. Rev. Phytopathol. 39:187-224.

McDermott, J. M., and McDonald, B. A. 1993. Gene flow in plant pathosystems. Annu. Rev. Phytopathol. 31:353-373.

McDonald, B. A., and Linde, C. 2002. Pathogen population genetics, evolutionary potential, and durable resistance. Annu. Rev. Phytopathol. 40:349-379.

Milgroom, M. G., Jimenez-Gasco, M. D., Olivares-Garcia, C., Drott, M. T., and Jimenez-Diaz, R. M. 2014. Recombination between clonal lineages of the asexual fungus Verticillium dahliae detected by genotyping by sequencing. PLoS One 9:e106740.
Nei, M. 1973. Analysis of gene diversity in subdivided populations. Proc. Natl. Acad. Sci. USA 70:3321-3323.

Nei, M. 1978. Estimation of average heterozygosity and genetic distance from a small number of individuals. Genetics 89:583-590.

Peakall, R., and Smouse, P. E. 2012. GenAlEx 6.5: Genetic analysis in Excel. Population genetic software for teaching and research-an update. Bioinformatics 28:2537-2539.

Pegg, G. 1974. Verticillium diseases. Rev. Plant Pathol. 53:156-182.

Pegg, G. F., and Brady, B. L. 2002. Verticillium Wilts. CABI Publishing, New York.

Puri, K. D., Saucedo, E. S., and Zhong, S. 2012. Molecular characterization of Fusarium head blight pathogens sampled from a naturally infected disease nursery used for wheat breeding programs in China. Plant Dis. 96: 1280-1285.

Qin, Q. M., Vallad, G. E., Wu, B. M., and Subbarao, K. V. 2006. Phylogenetic analyses of phytopathogenic isolates of Verticillium spp. Phytopathology 96:582-592.

Sandoya, G. V., Gurung, S., Short, D. P., Subbarao, K. V., Michelmore, R. W., and Hayes, R. J. 2016. Genetics of resistance in lettuce to races 1 and 2 of Verticillium dahliae from different host species. Euphytica 213:20.

Schaible, L., Cannon, O. S., and Waddoups, V. 1951. Inheritance of resistance to Verticillium wilt in a tomato cross. Phytopathology 41:986-990.

Seidl, M. F., and Thomma, B. P. H. J. 2014. Sex or no sex: Evolutionary adaptation occurs regardless. BioEssays 36:335-345.

Short, D. P. G., Gurung, S., Gladieux, P., Inderbitzind, P., Atallah, Z. K., Nigro, F., Li, G., Benlioglu, S., and Subbarao, K. V. 2015a. Globally invading populations of the fungal plant pathogen Verticillium dahliae are dominated by multiple divergent lineages. Environ. Microbiol. 17:2824-2840.

Short, D. P. G., Gurung, S., Hu, X. P., Inderbitzin, P., and Subbarao, K. V. 2014a. Maintenance of sex-related genes and the co-occurrence of both mating types in Verticillium dahliae. PLoS One 9:e112145.

Short, D. P. G., Gurung, S., Maruthachalam, K., Atallah, Z. K., and Subbarao, K. V. 2014b. Verticillium dahliae race 2-specific PCR reveals a high frequency of race 2 strains in commercial spinach seed lots and delineates race structure. Phytopathology 104:779-785.

Short, D. P. G., Sandoya, G., Vallad, G. E., Koike, S. T., Xiao, C. L., Wu, B. M., Gurung, S., Hayes, R. J., and Subbarao, K. V. 2015b. Dynamics of Verticillium species microsclerotia in field soils in response to fumigation, cropping patterns, and flooding. Phytopathology 105:638-645.

Simko, I., Costanzo, S., Haynes, K. G., Christ, B. J., and Jones, R. W. 2004. Linkage disequilibrium mapping of a Verticillium dahliae resistance quantitative trait locus in tetraploid potato (Solanum tuberosum) through a candidate gene approach. Theor. Appl. Genet. 108:217-224.

Subbarao, K., Chassot, A., Gordon, T., Hubbard, J., Bonello, P., Mullin, R., Okamoto, D., Davis, R., and Koike, S. 1995. Genetic relationships and cross pathogenicities of Verticillium dahliae isolates from cauliflower and other crops. Phytopathology 85:1105-1112.

Subbarao, K. V., Hubbard, J. C., Greathead, A. S., and Spencer, G. A. 1997. Verticillium wilt. Pages 26-27 in: Compendium of Lettuce Diseases. R. M. Davis, K. V. Subbarao, R. N. Raid, and E. A. Kurtz, eds. The American Phytopathological Society, St. Paul, MN.

Usami, T., Momma, N., Kikuchi, S., Watanabe, H., Hayashi, A., Mizukawa, M., Yoshino, K., and Ohmori, Y. 2016. Race 2 of Verticillium dahliae infecting tomato in Japan can be split into two races with differential pathogenicity on resistant rootstocks. Plant Pathol. 66:230-238.

Vallad, G. E., Qin, Q. M., Grube, R., Hayes, R. J., and Subbarao, K. V. 2006. Characterization of race-specific interactions among isolates of Verticillium dahliae pathogenic on lettuce. Phytopathology 96:1380-1387.

Vallad, G. E., and Subbarao, K. V. 2008. Colonization of resistant and susceptible lettuce cultivars by a green fluorescent protein-tagged isolate of Verticillium dahliae. Phytopathology 98:871-885.

Vercauteren, A., De Dobbelaere, I., Grunwald, N. J., Bonants, P., Van Bockstaele, E., Maes, M., and Heungens, K. 2010. Clonal expansion of the Belgian Phytophthora ramorum populations based on new microsatellite markers. Mol. Ecol. 19:92-107.

Vining, K., and Davis, T. 2009. Isolation of a Ve homolog, $m V e 1$, and its relationship to Verticillium wilt resistance in Mentha longifolia (L.) Huds. Mol. Genet. Genomics 282:173-184.

Weber, J. L., and Wong, C. 1993. Mutation of human short tandem repeats. Hum. Mol. Genet. 2:1123-1128.

Yeh, F. C., Yang, R. C., Boyle, T. B., Ye, Z., and Mao, J. X. 1997. POPGENE, the user-friendly shareware for population genetic analysis. Molecular Biology and Biotechnology Centre, University of Alberta, Edmonton, AB, Canada.

Zhan, J., Kema, G. H., Waalwijk, C., and McDonald, B. A. 2002. Distribution of mating type alleles in the wheat pathogen Mycosphaerella graminicola over spatial scales from lesions to continents. Fungal Genet. Biol. 36: 128-136. 